\title{
Effect of meteorological factors on first episode and recurrence of primary spontaneous pneumothorax
}

\author{
Kerim Tülüce ${ }^{1 *} \oplus$, Gokçen Sevilgen ${ }^{1}$
}

\begin{abstract}
SUMMARY
OBJECTIVE: In this study, we evaluated the clinical characteristics and seasonal distribution of patients with primary spontaneous pneumothorax and examined the relationships between meteorological factors and pneumothorax development overall and in terms of first episode and recurrence. METHODS: The hospital records of 168 pneumothorax patients treated in our clinic between January 2016 and December 2020 were reviewed retrospectively. A cluster was defined as two or more patients with pneumothorax presenting within three consecutive days. Meteorological factors were compared between days with and without pneumothorax patients. This comparison was based on meteorological data from the day of symptom onset (D), the day before symptom onset (D1), and the difference between those days (D-D1). Meteorological data from the index day (D) were also compared between patients with first episode and recurrence of pneumothorax.

RESULTS: The study included 149 (88.7\%) men and 19 (11.3\%) women. The mean age was $25.02 \pm 6.97$ (range, 17-35; median, 26) years. Of note, 73 (43.4\%) patients underwent surgery. The highest number of patients presented in November ( $n=19,11.3 \%)$. In terms of season, most presentations occurred in autumn. Humidity was significantly lower on recurrence days compared with first episode ( $p=0.041)$.

CONCLUSION: Our results indicated that meteorological factors (i.e., atmospheric pressure, humidity, wind speed, temperature, and precipitation) were not associated with pneumothorax development. By comparing the patients with first episode and recurrence, the humidity was significantly lower in the recurrence group.

KEYWORDS: Pneumothorax. Meteorology. Humidity. Recurrence.
\end{abstract}

\section{INTRODUCTION}

Pneumothorax is characterized by air accumulation in the pleural space followed by lung collapse and is classified into spontaneous, traumatic, or iatrogenic ${ }^{1}$. Primary spontaneous pneumothorax (PSP) usually occurs in young, healthy individuals (aged 10-40 years) in the absence of any underlying lung disease ${ }^{2}$. Recurrence refers to repeated episodes of pneumothorax that occur after an initial episode. Studies have reported the recurrence rates of $13-49 \%$ in the first year and above $50 \%$ in 5-year follow-up ${ }^{3}$. Rupture of a bleb, bulla, or subpleural pores in the lung apex has been implicated in the pathogenesis of PSP, but the etiological factors remain unclear. Asthenic body type, smoking, young age, and male sex are recognized as risk factors for $\mathrm{PSP}^{4}$. Apart from these, genetic causes, environmental factors, and meteorological conditions have also been implicated.

There are publications in the literature demonstrating a relationship between PSP and meteorological factors and air pollution. These studies have investigated factors, such as air pollution, atmospheric pressure (AP), humidity changes, air temperature, daily rainfall, and wind speed, and some have shown a relationship between these factors and the development of spontaneous pneumothorax.

The present study investigated the clinical characteristics and seasonal distribution of PSP patients and evaluated the associations between meteorological factors and PSP development overall and in patients with first episode and recurrence.

\section{METHODS}

The hospital records of 168 PSP patients treated in the thoracic surgery department of Recep Tayyip Erdogan University Education and Research Hospital over the 5-year period between January 2016 and December 2020 were reviewed retrospectively. All patients with PSP, who aged between 17 and 35 years, presented to our clinic, and had complete records, were included in the study. Patients, who aged $<17$ years or $>35$ years, whose records were incomplete, or who presented to our hospital from outside the region, were excluded.

Demographic data collected from the patients' records included age, gender, PSP side, a first episode or recurrence, length of hospital stay, smoking status, treatment received,

${ }^{1}$ Recep Tayyip Erdoğan University, Education and Research, Department Thoracic Surgery - Rize, Turkey.

*Corresponding author: ktuluce@yahoo.com

Conflicts of interest: the authors declare there is no conflicts of interest. Funding: none.

Received on October 20, 2021. Accepted on October 27, 2021. 
body mass index (BMI), and reasons for undergoing surgery. The day of PSP occurrence was defined as the day of symptom onset (chest pain and shortness of breath) as determined from the patients' records instead of the day of presentation. Two or more patients presenting with PSP within three consecutive days were defined as a cluster 5 .

Wind speed, humidity, temperature, AP, and daily precipitation data were obtained from the National General Directorate of Meteorology. There were no missing data among the datasets. Meteorological factors were compared between days with and without PSP cases based on data from the day of symptom onset (D), the day before symptom onset (D1), and the difference between these days (D-D1). Meteorological factors on the index day (D) were also compared between patients with first episode and those with recurrence of PSP.

\section{Statistical analysis}

Analyses were performed using SPSS version 18.0 software (SPSS Inc., Chicago, IL, USA). Continuous data were presented as mean and standard deviation, and categorical data were presented as numbers and percentages. The distribution of continuous data was evaluated using the Kolmogorov-Smirnov test. The Mann-Whitney U-test was used to analyze relationships between meteorological data and days with and without PSP cases and between days with first episode and recurrence of PSP. A statistical significance level of $\mathrm{p}<0.05$ was used for all tests.

\section{RESULTS}

A total of 168 patients with PSP treated between January 2016 and December 2020 were included in the study. Of these, 149 $(88.7 \%)$ were men, and $19(11.3 \%)$ were women. The mean age was $25.02 \pm 6.97$ (range, 17-35) years, and the median age was 26 years. Of note, $73(43.4 \%)$ patients underwent surgery. The mean length of hospital stay for patients not treated surgically was $6.26 \pm 2.33$ days, while that of patients who underwent surgery was $10.38 \pm 4.14$ (median, 9.8) days. The mean BMI of patients was 21.67 \pm 3.12 , and $118(70.2 \%)$ patients had smoking history. The most common symptoms were chest pain (90.4\%), shortness of breath (17.7\%), and cough (2.9\%). Pneumothorax was on the right side in 103 (61.3\%) patients and on the left side in $65(38.7 \%)$ patients. Surgery was performed in $38(52.1 \%)$ patients due to recurrent pneumothorax, in $32(43.8 \%)$ patients due to prolonged air leak, and in 3 (4.1\%) patients for other reasons (hemothorax in 2 patients and expansion defect in 1 patient) (Table 1). The highest number of patients presented in November $(n=19,11.3 \%)$. In terms of season, most presentations occurred in autumn.
The 168 PSP episodes occurred on 158 different days. A total of 68 (43\%) patients presented in 30 PSP clusters. The mean number of cases in each cluster was found to be $2.1 \pm 0.6$ (range, 2-4 cases).

The $\mathrm{AP}(\mathrm{hPa})$, wind speed $(\mathrm{km} / \mathrm{h})$, humidity $(\%)$, temperature $\left({ }^{\circ} \mathrm{C}\right)$, and amount of precipitation $(\mathrm{mm})$ were evaluated from the meteorological data of 158 days with PSP symptom onset and the 1,668 days without PSP cases. There were no statistically significant differences between days with and without PSP in terms of meteorological parameters on the index day $(\mathrm{D})$, the day before (D1), or the difference between these days (D-D1) (Table 2).

The comparison of the first episode and recurrence of PSP patients in terms of meteorological data showed that humidity was significantly lower on days with recurrence $(\mathrm{p}=0.041)$ (Table 3$)$.

\section{DISCUSSION}

Apart from the commonly known factors in the etiology of PSP, one of the current topics is the effect of meteorological factors. Studies have suggested possible associations between

Table 1. Characteristics of patients with primary spontaneous pneumothorax $(n=168)$.

\begin{tabular}{|c|c|}
\hline & Mean \pm SD or $n(\%)$ \\
\hline Age & $25.02 \pm 6.97$ \\
\hline \multicolumn{2}{|l|}{ Gender } \\
\hline Male & $149(88.7)$ \\
\hline Female & 19 (11.3) \\
\hline Smoker & $118(70.2)$ \\
\hline Mean BMI (kg/m²) & $21.67 \pm 3.12$ \\
\hline \multicolumn{2}{|l|}{ Side of PSP } \\
\hline Right & $103(61.3)$ \\
\hline Left & $65(38.7)$ \\
\hline \multicolumn{2}{|l|}{ Length of hospital stay } \\
\hline Surgical patients & $10.38 \pm 4.14$ \\
\hline Nonsurgical patients & $6.26 \pm 2.33$ \\
\hline \multicolumn{2}{|l|}{ Reason for surgery } \\
\hline Recurrence & $38(52.1)$ \\
\hline Prolonged air leaked & $32(43.8)$ \\
\hline Other reasons & $3(4.1)$ \\
\hline \multicolumn{2}{|l|}{ Number of PSP episodes } \\
\hline First episode & $106(63.1)$ \\
\hline Recurrence (2 or more) & $62(36.9)$ \\
\hline
\end{tabular}

BMI: body mass index; SD: standard deviation; PSP: primary spontaneous pneumothorax. 
Table 2. Comparison of meteorological factors on days with and without cases of primary spontaneous pneumothorax.

\begin{tabular}{|c|c|c|c|}
\hline Parameter & $\begin{array}{c}\text { Days without PSP } \\
\text { (1,668 days) } \\
\text { mean } \pm \text { SD }\end{array}$ & $\begin{array}{l}\text { Days with PSP } \\
\text { (158 days) } \\
\text { mean } \pm \text { SD }\end{array}$ & p \\
\hline \multicolumn{4}{|c|}{ Wind speed (km/h) } \\
\hline $\mathrm{D}$ & $5.23 \pm 2.52$ & $5.43 \pm 2.68$ & 0.329 \\
\hline D1 & $5.25 \pm 2.53$ & $5.22 \pm 2.60$ & 0.878 \\
\hline D-D1 & $-0.02 \pm 3.02$ & $0.22 \pm 3.18$ & 0.348 \\
\hline \multicolumn{4}{|l|}{ Humidity (\%) } \\
\hline $\mathrm{D}$ & $58.86 \pm 15.51$ & $59.15 \pm 17.06$ & 0.821 \\
\hline D1 & $59.06 \pm 15.57$ & $57.09 \pm 16.47$ & 0.132 \\
\hline D-D1 & $-0.21 \pm 16.48$ & $2.06 \pm 17.66$ & 0.100 \\
\hline \multicolumn{4}{|c|}{ Atmospheric pressure (hPa) } \\
\hline $\mathrm{D}$ & $1015.36 \pm 6.11$ & $1015.55 \pm 5.72$ & 0.714 \\
\hline D1 & $1015.34 \pm 6.09$ & $1015.75 \pm 5.96$ & 0.426 \\
\hline D-D1 & $0.02 \pm 4.12$ & $-0.20 \pm 4.14$ & 0.533 \\
\hline \multicolumn{4}{|c|}{ Temperature $\left({ }^{\circ} \mathrm{C}\right)$} \\
\hline $\mathrm{D}$ & $15.89 \pm 6.91$ & $15.56 \pm 6.88$ & 0.558 \\
\hline D1 & $15.90 \pm 6.91$ & $15.49 \pm 6.87$ & 0.469 \\
\hline D-D1 & $0.00 \pm 1.74$ & $0.07 \pm 2.01$ & 0.633 \\
\hline \multicolumn{4}{|c|}{ Precipitation (mm) } \\
\hline $\mathrm{D}$ & $5.70 \pm 12.98$ & $6.46 \pm 15.55$ & 0.493 \\
\hline D1 & $5.66 \pm 12.90$ & $6.91 \pm 16.18$ & 0.258 \\
\hline D-D1 & $0.01 \pm 16.22$ & $-0.45 \pm 20.31$ & 0.736 \\
\hline
\end{tabular}

D: index day; D1: 1 day earlier; hPa: hectopascal; SD: standard deviation; PSP: primary spontaneous pneumothorax.

Table 3. Comparison of meteorological factors on days with cases of first episode and recurrence of primary spontaneous pneumothorax.

\begin{tabular}{l|c|c|c}
\multirow{2}{*}{ Parameter } & \multicolumn{2}{|c|}{ Attack number } & \multirow{2}{*}{$\mathbf{p}$} \\
\cline { 2 - 4 } & $\begin{array}{c}\text { First episode }(\mathbf{n = 1 0 6}) \\
\text { Mean } \pm \text { SD }\end{array}$ & $\begin{array}{c}\text { Recurrence(n=62) } \\
\text { Mean } \pm \text { SD }\end{array}$ & 0.527 \\
\hline Wind speed $(\mathrm{km} / \mathrm{h})$ & $5.30 \pm 2.26$ & $5.57 \pm 3.19$ & 0.041 \\
\hline Humidity $(\%)$ & $61.79 \pm 16.36$ & $56.24 \pm 17.73$ & 0.355 \\
\hline AP $(\mathrm{hPa})$ & $1015.22 \pm 5.15$ & $1016.06 \pm 6.47$ & 0.180 \\
\hline Temperature $\left({ }^{\circ} \mathrm{C}\right)$ & $16.05 \pm 6.86$ & $14.57 \pm 6.98$ & 0.513 \\
\hline
\end{tabular}

AP: atmospheric pressure; hPa: hectopascal; SD: standard deviation.

meteorological factors and myocardial infarction, asthma, abdominal aortic rupture, facial paralysis, and sudden hearing $\operatorname{loss}^{6}$. There are also reports of pneumothorax due to pressure changes while diving and during flights ${ }^{7}$.

Humidity is a parameter evaluated in many studies, but most could not demonstrate a relationship with $\mathrm{PSP}^{8,9}$. Ozenne et al. ${ }^{10}$ reported that spontaneous pneumothorax peaked in winter and summer, and its incidence was significantly associated with low humidity. They stated that dry air results in inadequate humidification of the airways and that the subsequent bronchoconstriction may play a role in the physiopathology of pneumothorax. Bozkurt et al. ${ }^{11}$ found that the mean change between daily 
maximum and minimum humidity levels was $43.1 \pm 13.4 \%$ on the days when 95 patients presented with spontaneous pneumothorax and $38.6 \pm 16.2 \%$ on the other days. In our study, there was no relationship between PSP and humidity, but when the first episode and recurrence patient groups were compared, the humidity level was significantly lower on the days when patients presented with recurrence. Therefore, we believed that a decrease in humidity may be a factor in the development of recurrence.

A relationship between wind speed and spontaneous pneumothorax has been mentioned in some publications. Ogata et al. ${ }^{8}$ observed a relationship between PSP and high wind speed in their study involving 110 cases. Schiemann et al. ${ }^{12}$ conducted a study on 220 patients and found that high wind speed and low AP were associated with spontaneous pneumothorax. In contrast, Bertolucci et al. ${ }^{13}$ reported a relationship between spontaneous pneumothorax and low wind speed. In a series of 195 cases analyzed by Yamac et al. ${ }^{14}$, the wind speed was significantly lower on the days when patients presented with spontaneous pneumothorax. In their two-center study, including 494 patients, Daş et al..$^{15}$ demonstrated that spontaneous pneumothorax was associated with northern winds and low wind speed and reported that low temperature and sudden temperature changes could also be factors.

The amount of precipitation has also been investigated, though less frequently. In a series of 669 patients, Özpolat et al. ${ }^{16}$ found significantly more precipitation on the days when patients presented with spontaneous pneumothorax and in the 2-day period before these days. Similarly, Alifano et al..$^{5}$ reported an increase in spontaneous pneumothorax on stormy days, which they defined as thunder and lightning with heavy rainfall.

Similar to other meteorological factors, our literature review yielded different results related to temperature ${ }^{5,17,18}$. Özpolat et al. ${ }^{16}$ showed that PSP was associated with low temperature but noted that this might be a cofactor rather than having a direct effect. In another study of 200 patients, Yaksi et al. ${ }^{19}$ also found that a reduction in temperature was significantly associated with the development of PSP. Sahinoglu et al..$^{20}$ reported that temperature higher than $15^{\circ} \mathrm{C}$ may contribute to the development of PSP and that when compared with blood group, people with blood group $\mathrm{O}$ were more resistant to temperature changes. In a study by Zhang et al. ${ }^{21}$, involving 337 patients, an increase in mean temperature and low AP were reported to play a role in PSP development.

In contrast, changes in AP are the most popular area of study, with the most related articles and the largest patient series. In a recent study, Akyl et al. ${ }^{22}$ evaluated 1,097 PSP patients treated in a 4-year period and reported that low pressure and sudden decrease in pressure during the day might be the factors in the development of pneumothorax. In their study, there was a decrease in pressure on $65 \%$ of the days on which PSP cases presented and an increase in pressure on $65 \%$ of the days with no PSP cases. Another large study by Haga et al. ${ }^{23}$ included 1,051 patients with PSP and showed that the AP fell by $0.6 \mathrm{hPa}$ on the days of PSP cases compared with the day before. In our literature review, there were also a substantial number of studies in which no relationship was detected between AP and pneumothorax, as in our study $y^{24}$.

In their study in 2007, Alifano et al. ${ }^{5}$ defined a cluster as a period of 3 days in which two or more patients presented and reported a cluster rate of $84 \%$ in their study involving 294 patients. This rate was $70.5 \%$ in a 699 case series reported by Özpolat et al. ${ }^{16}$. In these three studies, clustering was associated with low AP. Haga et al. ${ }^{23}$ reported 597 clusters in a study of 1,051 cases, with $88 \%$ of the patients in these clusters. The mean number of pneumothorax cases per cluster was 3.2 in the study by Alifano and $2.5 \pm 0.8$ in the study by Özpolat et al. In our study, $43 \%$ of the PSP cases formed clusters, and the mean number of cases per cluster was $2.1 \pm 0.6$.

In terms of seasonality, we noted in our literature review that PSP was most common in autumn and in the months of June and November ${ }^{11,18}$. Similarly, in our study, we found that the number of patients was higher in autumn and November.

The main limitations of the present study are its retrospective design and our inability to conduct multivariate analysis due to the small number of patients.

\section{CONCLUSION}

It is clear from many studies conducted on this subject that the relationship between the meteorological factors and the development of pneumothorax has yet to be proven definitively. We believe that detailed studies comparing different predisposing factors with meteorological data will provide more definitive information in the future.

\section{ETHICAL APPROVAL}

Approval for this retrospective, descriptive, single-center study was obtained from the Clinical Research Ethics Committee of Recep Tayyip Erdoğan University Faculty of Medicine Education and Research Hospital (decision no: 2020/193, dated September 3, 2020).

\section{AUTHORS' CONTRIBUTIONS}

KT: conceptualization, data curation, formal analysis, investigation, writing - original draft. GS: conceptualization, supervision, writing - review $\&$ editing. 


\section{REFERENCES}

1. Papagiannis A, Lazaridis G, Zarogoulidis K, Papaiwannou A, Karavergou A, Lampaki S, et al. Pneumothorax: an up to date "introduction". Ann Transl Med. 2015;3(4):53. https://doi. org/10.3978/j.issn.2305-5839.2015.03.23

2. MacDuff A, Arnold A, Harvey J, BTS Pleural Disease Guideline Group. Management of spontaneous pneumothorax: British Thoracic Society Pleural Disease Guideline 2010. Thorax. 2010;65(Suppl 2):ii18-31. https://doi.org/10.1136/ thx.2010.136986

3. Ouanes-Besbes L, Golli M, Knani J, Dachraoui F, Nciri N, El Atrous S, et al. Prediction of recurrent spontaneous pneumothorax: CT scan findings versus management features. Respir Med. 2007;101(2):230-6. https://doi.org/10.1016/j. rmed.2006.05.016

4. Kepka S, Dalphin JC, Parmentier AL, Pretalli JB, Gantelet M, Bernard N, et al. Primary spontaneous pneumothorax admitted in emergency unit: does first episode differ from recurrence? A cross-sectional study. Can Respir J. 2017;2017:2729548. https:// doi.org/10.1155/2017/2729548

5. Alifano M, Forti Parri SN, Bonfanti B, Arab WA, Passini A, Boaron $M$, et al. Atmospheric pressure influences the risk of pneumothorax: beware of the storm! Chest. 2007;131(6):1877-82. https://doi. org/10.1378/chest.06-2206

6. Danet S, Richard F, Montaye M, Beauchant S, Lemaire B, Graux C, et al. Unhealthy effects of atmospheric temperature and pressure on the occurrence of myocardial infarction and coronary deaths. A 10-year survey: the Lille-World Health Organization MONICA project (monitoring trends and determinants in cardiovascular disease). Circulation. 1999;100(1):E1-7. https:// doi.org/10.1161/01.cir.100.1.e1

7. Dermksian G, Lamb LE. Spontaneous pneumothorax in apparently healthy flying personnel. Ann Intern Med. 1959;51(1):39-51. https://doi.org/10.7326/0003-4819-51-1-39

8. Ogata H, Matsumoto K, Nakatomi K, Nakashima N, Shoji F, Koto $\mathrm{H}$. Seasonal and meteorological impacts on primary spontaneous pneumothorax. J Thorac Dis. 2018;10(7):3957-64. https://doi. org/10.21037/jtd.2018.06.17

9. Mishina T, Watanabe A, Miyajima M, Nakazawa J. Relationship between onset of spontaneous pneumothorax and weather conditions. Eur J Cardiothorac Surg. 2017;52(3):529-33. https:// doi.org/10.1093/ejcts/ezx128

10. Ozenne G, Poignie P, Lemercier JP, Nouvet G, Grancher G. Meteorological conditions and spontaneous pneumothorax. Retrospective study of 165 cases in the Rouen area. Rev Pneumol Clin. 1984;40(1):27-33. PMID: 6718945

11. Bozkurt S, Tokur M, Okumus M, Kahraman H, Ozkan F, Tabur A. Role of meteorological changes in occurrence of spontaneous pneumothorax and clinical characteristics of patients. Turk J Thorac Cardiovasc Surg. 2013;21(1):95-9. https://doi.org/10.5606/tgkdc. dergisi.2013.6594
12. Schieman C, Graham A, Gelfand G, McFadden SP, Tiruta C, Hill $M D$, et al. Weather and chinook winds in relation to spontaneous pneumothoraces. Can J Surg. 2009;52(5):E151-5. PMID: 19865545

13. Bertolaccini L, Alemanno L, Rocco G, Cassardo C. Air pollution, weather variations and primary spontaneous pneumothorax. J Thorac Dis. 2010;2(1):9-15. PMID: 22263010

14. Yamac ME, Karapolat S, Turkyilmaz A, Seyis KN, Tekinbas C. Relationship of spontaneous pneumothorax cases seen in Eastern Black Sea region with meteorological changes. Int J Biometeorol. 2017;61(8):1493-8. https://doi.org/10.1007/s00484-017-1327-z

15. Da? M,Alar T,Delice O, Gedik? E, Bardakci O,Akman C,etal. The effect of meteorological variables on spontaneous pneumothorax in two regions with different altitudes. Int J Biometeorol. 2021;65(4):50311. https://doi.org/10.1007/s00484-020-02040-6

16. Özpolat B, Gözübüyük A, Koçer B, Yazkan R, Dural K, Genç O. Meteorological conditions related to the onset of spontaneous pneumothorax. Tohoku J Exp Med. 2009;217(4):329-34. https:// doi.org/10.1620/tjem.217.329

17. Carrido García JA, Cabezudo Hernández MA, Fernández Rego G, Fernández Bustillo E. Association between falls in atmospheric pressure and spontaneous pneumothorax. Eur J Respir Dis. 1985;66(3):230. PMID: 3979489

18. Celik B, Kefeli Celik H, Hamzaçebi H, Demir H, Furtun K, Ortamevz C. The role of meteorological conditions on the development of spontaneous pneumothorax. Thorac Cardiovasc Surg. 2009;57(7):409-12. https://doi.org/10.1055/s-0029-1185721

19. Yak? ? O, Özel A, Ünal M, Öztürk F, Kılıçgün A. The association between pneumothoraxonset and meteorological parameters and air pollution. Turk Gogus Kalp Damar Cerrahisi Derg. 2020;28(4):65661. https://doi.org/10.5606/tgkdc.dergisi.2020.19610

20. Sahinoglu T, Katrancioglu O. Impact of weather conditions and blood groups on primary spontaneous pneumothorax. Curr Thorac Surg. 2020;5(2):59-63. https://doi.org/10.26663/cts.2020.00013

21. Zhang GJ, Gao R, Fu JK, Jin X, Zhang Y, Wang Z. Climatic conditions and the onset of primary spontaneous pneumothorax: an investigation of the influence of solar terms. Med Princ Pract. 2012;21(4):345-9. https://doi.org/10.1159/000336213

22. Akyıl M, Tezel C,, Evman S, Tokgöz Akyll F, Vayvada M, Bayram S, et al. Correlation between meteorological changes and primary spontaneous pneumothorax: Myth or fact? Turk Gogus Kalp Damar Cerrahisi Derg. 2018;26(3):436-40. https://doi.org/10.5606/ tgkdc.dergisi.2018.1549

23. Haga T, Kurihara M, Kataoka H, Ebana H. Influence of weather conditions on the onset of primary spontaneous pneumothorax: positive association with decreased atmospheric pressure. Ann Thorac Cardiovasc Surg. 2013;19(3):212-5. https://doi. org/10.5761/atcs.oa.12.01884

24. Heyndrickx M, Le Rochais JP, Icard P, Cantat O, Zalcman G. Do atmospheric conditions influence the first episode of primary spontaneous pneumothorax? Interact Cardiovasc Thorac Surg. 2015;21(3):296-300. https://doi.org/10.1093/icvts/ivv145 